\title{
Call for papers: Special Issue of Earth, Planets and Space (EPS) Coupling Processes in the Equatorial Atmosphere (CPEA)
}

The International Symposium on Coupling Processes in the Equatorial Atmosphere (CPEA Symposium) was held in March 20-23, 2007 at Kyoto University Clock Tower Centennial Hall, Kyoto, Japan. A number of good papers were presented in the symposium that deepened our understanding of a broad range of dynamical, electrodynamical and photochemical coupling processes that occur in the equatorial atmosphere and ionosphere. Special attention was paid to wave excitation by cumulus convection, and coupling attributable to convectively-excited small-scale and large-scale waves. Atmospheric and ionospheric processes and their coupling in the equatorial and low-latitude regions were also the main interest of the symposium.

Based on the success of the CPEA Symposium, we would like to solicit papers from the Symposium for publication in the Journal EPS (Earth, Planets and Space). The publication will not be limited to the papers presented in the CPEA Symposium; other papers covering the topics of the symposium are also welcome to the special issue. Contributors to the special issue should submit their papers to the EPS editorial office either by post or by e-mail (eps@ terrapub.co.jp), following the instructions for regular EPS submission. For details, please visit the following web page:

http://www.terrapub.co.jp/journals/EPS and click on "Information for Contributors."

Please state "For Special issue for the Coupling Processes in the Equatorial Atmosphere (CPEA)" clearly in the covering letter that accompanies the submission. We encourage electronic submission. Once the papers are accepted for publication, the editorial office will send instructions to the authors for preparing the final manuscript. The deadline for manuscript submission for the special issue is 30 September 2007, and we hope to publish the special issue in April 2008.

For more information on this special issue, please contact the corresponding editor (M. Yamamoto, yamamoto@rish. kyoto-u.ac.jp); questions on manuscript preparation should be addressed to the EPS editorial office.

Note: EPS accepts manuscripts of original research contributions only, and so-called "review papers" will not be accepted.

Guest Editors: Shoichiro Fukao, RISH, Kyoto University, Japan Mamoru Yamamoto, RISH, Kyoto University, Japan Tetsuo Nakazawa, Meteorological Research Institute, Japan S. Gurubaran, Indian Institute of Geomagnetism, India Nanan Balan, University of Sheffield, UK 